\title{
CHARACTERIZATION OF FATTY ACIDS IN SAMBO OIL (CUCURBITA FICIFOLIA L.) FROM ECUADOR
}

\author{
CARRILLO $W^{1 *}$, CARRILLO C ${ }^{1}$, CARPIO $C^{1}$, MORALES $D^{1}$,VILCACUNDO $^{2}$, ÁLVAREZ M $^{1}$, SILVA $^{1}$
}

${ }^{1}$ Laboratory of Functional Foods, Faculty of Foods Science and Engineering, Technical University of Ambato. Av. Los Chasquis y Rio Payamino. Campus Huachi, CP 1801334, Ambato-Ecuador. ${ }^{2}$ Faculty of Agricultural Sciences Natural Resources and Environment, Agronomical Engineering, Bolivar State University. Academic Campus "Alpachaca" Av. Ernesto Che Guevara s/n y Av. Gabriel Secaira. EC.020150. Guaranda, Ecuador. Email: Wi.carrillo@uta.edu.ec

Received: 06 October 2016, Revised and Accepted: 1 October 2016

\section{ABSTRACT}

Objective: The aim of this study was to identify fatty acids in a sambo oil sample cultivated in Ecuador.

Methods: Sambo oil was obtained from sambo seeds using the cold pressing method. Fatty acids analysis was carried out using the gas chromatography with a mass selective detector (MSD) and using the database Library NIST14.L to identify the compounds.

Results: Sambo seeds have a high content of unsaturated fatty acids with $41.36 \%$ of oleic acid. Sambo oil has $37.77 \%$ of polyunsaturated fatty acids, of which $3.79 \%$ $₫ 6 \alpha$ - linoleic and $33.98 \%$ of $₫ 3 \alpha$ - linolenic. Sambo seeds only have $9.33 \%$ of palmitic acid.

Conclusions: Sambo seed is a good source of monounsaturated fatty acids with a good content of $₫ 3 \alpha$ - linolenic. This profile enables their use as a good and healthy oil to be used in the food industry in Ecuador.

Keywords: Sambo, Cucurbita ficifolia, Fatty acids, Gas chromatography-mass selective detector, Methyl ester

(C) 2018 The Authors. Published by Innovare Academic Sciences Pvt Ltd. This is an open access article under the CC BY license (http://creativecommons. org/licenses/by/4. 0/) DOI: http://dx.doi.org/10.22159/ajpcr.2018.v11i2.15545

\section{INTRODUCTION}

(Cucurbita ficifolia L), named Sambo in the central region of Ecuador, is a member of the Cucurbitaceae family also known as cucurbits belonging to a big group of approximately 130 genera and 800 species [1]. This plant can be cultivated in warmer regions worldwide and be used as a popular food. Seeds of pumpkin are consumed either roasted or raw and used in cooking and baking as an ingredient of cereals, bread, cakes, and salads. Sambo seeds are consumed habitually in Ecuador such as dried fruits and as an ingredient of different traditional foods. Pumpkin seed oil is accepted as edible oil and as a nutraceutical product. Pumpkin seed and seed oil are a rich natural source of phytosterols [2], proteins, polyunsaturated fatty acids (PUFAs), antioxidant vitamins, carotenoids, and tocopherols as well as various essential elements. These components are considered to provide many health benefits [3].

Pumpkin seeds contain oil with a high proportion of fatty acid components such as palmitic (C 16:0, 10.68\%), palmitoleic (C 16: 1, $0.58 \%$ ), stearic (C 18:0,8.67\%), oleic (C 18: 1, 38.42\%), linoleic (C 18:2, $39.84 \%$ ), linolenic (C18: $3,0.68 \%$ ), and gadoleic (C20: 1, 1.14\%). The total saturated fatty acids amount to $19.35 \%$, and the total unsaturated fatty acids amount to $80.65 \%$ [4]. Different studies have reported some biological activities such as antidiabetic, anti-inflammatory, antioxidant, antimicrobial, and anticancer activities of the different isolate compounds of pumpkin seeds $[5,6]$.

The aim of this work was to characterize the composition of fatty acids methyl esters (FAMEs) present in sambo oil samples cultivated in Ecuador using the gas chromatography-mass selective detector (GC-MSD). The knowledge acquired in this study will help to determine the potential of sambo seed oil to be commercially exploited for industrial applications and incorporation into functional foods to help human health in the central region of Ecuador.

\section{METHODS}

\section{Oil extraction}

Sambo is cultivated in the central region of Ecuador. Sambo oil sample was obtained from sambo seeds using the cold pressed method. Oil was then stored at $4.0 \pm 2{ }^{\circ} \mathrm{C}$. Oil extraction was conducted using a Soxhlet apparatus for approximately $5 \mathrm{~h}$ with hexane as solvent, with a solid-tosolvent ratio of $1 / 7 \mathrm{~m} / \mathrm{v}$. After the extraction process, the flask contents were filtered, and the liquid fraction containing the lipid extract and solvent was poured into a $250-\mathrm{mL}$ flask of a rotary film evaporator to remove the solvent. The obtained oil was collected, evaporated under nitrogen, weighed, and stored in sealed amber glass vials at $-20^{\circ} \mathrm{C}$ until analysis [7]

\section{Fatty acids analysis by GC-MSD}

The fatty acid composition of oil extracted from sambo seeds was analyzed by injecting fatty acid methyl esters [8] into an Agilent Technologies 7980Asystem GC (Agilent, Santa Clara, CA) equipped with a MSD 5977A GC/MSD, an auto-sampler7693, column (60 m $\times$ $250 \mu \mathrm{m} \times 0.25 \mu \mathrm{m}$, Agilent 122-7062). The oven temperature was programed as follows: From $80^{\circ} \mathrm{C}$, ramp 1: To $100^{\circ} \mathrm{C}$ at $20^{\circ} \mathrm{C} / \mathrm{min}$ during $1 \mathrm{~min}$; ramp 2: At $200^{\circ} \mathrm{C}$ at $25^{\circ} \mathrm{C} /$ min during $10 \mathrm{~min}$; and ramp 3: At $250^{\circ} \mathrm{C}$ at $2^{\circ} \mathrm{C} / \mathrm{min}$. The injector and detector temperatures were set at $250^{\circ} \mathrm{C}$. Helium was used as carrier gas at a linear flow velocity of $1.4 \mathrm{~mL} / \mathrm{min}$.

\section{RESULTS}

Sambo seeds are of green color with a weight between 0.2 and 0.220 grams and a size of approximaFtely $2.0 \mathrm{~cm}$ also can see pumpkin sambo cultivated in the central region of Ecuador (Fig. 1).

Sambo oil sample was obtained using the cold pressing method; fatty acids were subsequently methyl esterified. Fatty acids from sambo oil were identified using the GC/MSD. The precursor ions were compared 
to three database Library NIST14. L. Four majority peaks were identified with their associated retention time: $\mathrm{C} 16: 0$ with a retention time of $19.339 \mathrm{~min}$; C18:0 with a retention time of $26.083 \mathrm{~min}$; C18:1 with a retention time of $26.945 \mathrm{~min}$; and finally, C18:2 with a retention time of 28.710 min (Fig. 2).

The concentration of fatty acids was calculated with a peak area percentage. FAMEs were characterized as follows: C16:0 palmitic acid with $9.33 \%$ of fatty content, C18:0 stearic acid with $6.84 \%$ of fatty content, C18:1 oleic acid with $41.36 \%$ of fatty content, C18:2 linoleic acid with $3.79 \%$ of fatty content, and finally, C18:2 linoleic acid (LA) with $33.98 \%$ of fatty content (Table 1 ).

When the sambo fatty acid composition is compared to some common vegetable oils, it can be seen that olive oil has a high content of mono-

Table 1: Fatty acids composition of sambo seeds oil sample from Ecuador by GC/MSD analysis and their percentage

\begin{tabular}{llll}
\hline $\begin{array}{l}\text { Retention } \\
\text { time (min) }\end{array}$ & $\begin{array}{l}\text { Peak area } \\
\text { ratio }(\%)\end{array}$ & $\begin{array}{l}\text { Carbon number: Duoble } \\
\text { bound }\end{array}$ & $\begin{array}{l}\text { FAMEs } \\
\text { name }\end{array}$ \\
\hline 19.399 & 9.33 & C16:0 & Palmitic acid \\
26.083 & 6.84 & C18:0 & Stearic acid \\
26.945 & 41.36 & fl9 C18:1 & Oleic acid \\
28.710 & 33.98 & A9,12 C18:2 & Linoleic acid \\
\hline
\end{tabular}

FAMEs: Fatty acid methyl esters. GC/MSD: Gas chromatography/mass selective detector

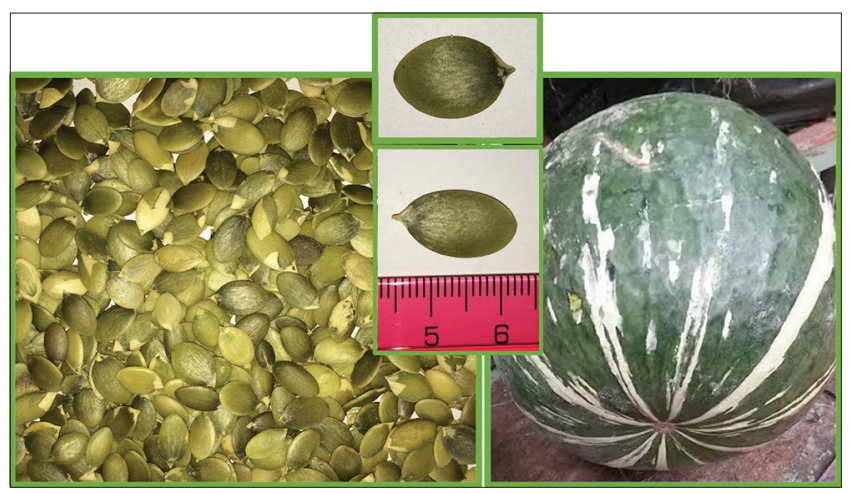

Fig. 1: Sambo seeds pumpkin without toast unsaturated fatty acids, C18:1 named oleic acid with $77.6 \%$ of oleic acid. It can be seen that sambo oil from Ecuador has a high content of mono-unsaturated fatty acids with a content of $41.36 \%$ of oleic acid. Sambo oil has also a high content of PUFAs with $33.98 \%$. Olive oil contains few omega- 6 and omega-3 fatty acids with $9.0 \%$ and $1.0 \%$, respectively (Table 2).

Many of the chronic conditions, cardiovascular diseases, diabetes, cancer, obesity, autoimmune diseases, rheumatoid arthritis, asthma, and depression are associated with an increased production of thromboxane A2, leukotriene B4, interleukin (IL)-1 $\alpha$, IL-6, tumor necrosis factor, and C-reactive protein. The previous molecule levels increase with increases in omega- 6 fatty acid intakes and decrease with increases in omega-3 fatty acid intakes [11,12].

\section{DISCUSSION}

Lipids are a major component of the human diet. Essential fatty acids (EFAs) are crucial dietary constituents for normal growth, development, and maintenance of internal homeostasis. High quantities of EFA may be found in plant seeds distributed in many regions of the world such as South America. These plants can provide oils with a high concentration of monounsaturated fatty acids that can help prevent cardiovascular diseases through several mechanisms [13]. The consumption of saturated fat in Ecuador is high, and the balance $\odot 3$ and $₫ 6$ is not correct in many processed foods. Dietary EFA includes LA, an n-6 FA, and alpha-linolenic acid (ALA), an n-3 FA. These EFA (omega 3 and omega 6) cannot be synthesized by the human body being necessary to supply them through dietary intake [14-16]. More importantly, EFA is metabolized with very long-chains (VLC) PUFAs. For instance, LA is converted to VLCPUFA arachidonic acid (AA), and ALA is converted to both VLCPUFAs eicosapentaenoic acid and docosahexaenoic acid. Both EFA and their associated VLCPUFA metabolites are important for various organism functions, including growth, immunity function, and cognitive development $[17,18]$.

The results obtained in this study are in accordance to fatty acids levels from sambo seeds reported in different studies in the science literature. Has been reported that fatty acid linoleic, oleic, palmitic and stearic acids are fatty acids predominant in Cucurbitaceae [20]. BernardoGil et al., 2004, reported a content of $14.7 \%$ oleic acid and $61.0 \%$ of linoleic acid (omega 6) in pumpkin seeds of $C$. ficifolia [21] while that Yu et al., 2004, reported $35.0 \%$ of oleic acid and 52.0\% of linoleic acid (omega 6) from $C$. ficifolia [22]. In other pumpkin seed, it reported the same situation, for example, Applequist et al., 2006, reported in

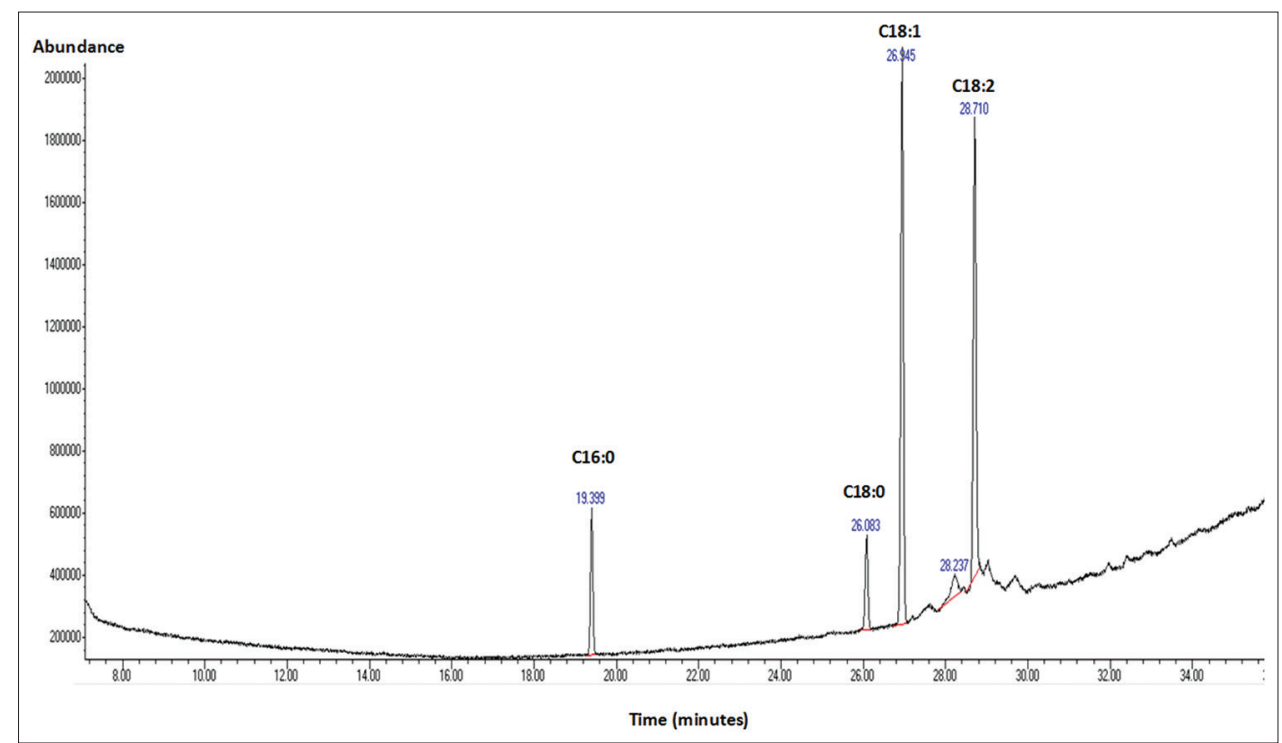

Fig. 2: Gas chromatography/mass selective detector analysis of fatty acids present in sambo oil sample 
Table 2: Fatty acid composition (\%) of seven vegetable oils

\begin{tabular}{|c|c|c|c|c|c|c|c|}
\hline Reference & Vegetable oil & C16:0 & C16:1 & C18:0 & C18:1 & C18:2 & C18:3 \\
\hline 9 and 10 & Olive oil & 13.8 & 1.4 & 2.8 & 71.6 & 9.00 & 1.0 \\
\hline 9 & Sunflower oil & 5.2 & 0.1 & 3.7 & 33.7 & 56.5 & 0.0 \\
\hline 9 & Palm oil & 44.8 & 0.0 & 4.6 & 38.9 & 9.5 & 0.4 \\
\hline 9 & Soybean oil & 10.1 & 0.0 & 4.3 & 22.3 & 53.7 & 8.1 \\
\hline 9 & Corn oil & 11.6 & 0.0 & 2.5 & 38.7 & 44.7 & 1.4 \\
\hline \multirow[t]{2}{*}{10} & Sacha inchi oil & 3.98 & 0.0 & 3.12 & 8.58 & 34.98 & 47.04 \\
\hline & Sambo oil & 9.33 & 0.0 & 6.84 & 41.36 & 33.98 & 0.0 \\
\hline
\end{tabular}

Cucurbita argyrosperma a content of $30.6 \%$ and $31.0 \%$ oleic acid and $45.4 \%$ and $44.2 \%$ linoleic acid in two varieties [23]. Tsaknis et al., 1997, reported $38.1 \%$ of oleic acid and $42.1 \%$ of linoleic acid from Cucurbita maxima [24]. Kamel et al., 1982, reported a content of $35.0 \%$ oleic acid and $41.0 \%$ [25]. In all pumpkin seeds oil, the content of linolenic acid is very low. In this study, the comportment of sambo seed oil was similar high content of oleic acid and linoleic acid without the presence of omega 3.

Oleic acid is recommended for FDA as an intake of monounsaturated fatty acids to reduce the risk of cardiovascular diseases. In the year 2004, the FDA authorized a health claim on olive oil on coronary heart disease: "Limited and not conclusive scientific evidence suggests that eating about two tablespoons ( $23 \mathrm{~g}$ ) of olive oil daily may reduce the risk of coronary heart disease due to the monounsaturated fat in olive oil. To achieve this possible benefit, olive oil is to replace a similar amount of saturated fat and not increase the total number of calories you eat in a day" (CFSAN/Office of Nutritional Products, 2004) [26]. A recent study from the European Food Safety Authority (EFSA) supports the effects of virgin olive oil phenols on low-density lipoprotein (LDL) oxidation(EFSA, 2011) [27]. Extra virgin olive oil contains monounsaturated fatty acid (oleic acid) and phenols compounds with antioxidant capacity. It is known that oxidation of LDL cholesterol is a key factor important in the development of the atherosclerosis, promoting the formation of foam cells in the subendothelial space of the vascular wall. Oleic acid and phenols help to prevent this oxidation when incorporated in the human diet daily $[28,29]$. Sambo oil has a good proportion of oleic acid, for this reason, sambo oil can be a good alternative in Ecuador to be used in the food industry due to its high nutritional quality for its high content of oleic acid.

\section{ACKNOWLEDGMENTS}

This study was supported by Universidad Técnica de Ambato, Ecuador (Project CPU-1373-2014-UTA) and (Project Canje de DeudaEspañaEcuador). This work has been reviewed in the English edition by Emilio Labrador.

\section{REFERENCES}

1. Perez-Gutierrez RM. Review of Cucurbita pepo (Pumpkin) its phytochemistry and pharmacology. Med Chem 2016;6:12-21.

2. Sabudak T. Fatty acid composition of seed and leaf oils of pumpkin. Walnut almond, maize, sunflower and melon. Chem Nat Compounds 2007;43:465-7.

3. Rabrenovic CC, Dimic EB, Novakovic MM, Tesevic VV, Basic ZN. Themost important bioactive components of cold pressed oil from different pumpkin (Cucurbita pipo L.) seeds. Food Sci Technol 2014;55:521-7.

4. Smith BD. The initial domestication of Cucurbita pepo in the Americas 10,000 years ago. Science 1997;276:932-4.

5. Nawirska-Olszańska A, Kita A, Biesiada A, Sokół-Łętowska A, Kucharska AZ. Characteristics of antioxidant activity and composition of pumpkin seed oils in 12 cultivars. Food Chem 2013;139:155-61.

6. Ríos JL, Andújar I, Escandell JM, Giner RM, Recio MC. Cucurbitacins as inducers of cell death and a rich source of potential anticancer compounds. Curr Pharm Des 2012;18:1663-76.

7. Gutiérrez LF, Rosada LM, Jiménez A. Chemical composition of Sacha Inchi (Plukenetiavolubilis L.) seeds andcharacteristics of their lipid fraction. Grasas Aceites 2011;62:76-83
8. Carrillo W, Carpio C, Morales D, Vilcacundo E, Alvarez m, Silva M. Content of fatty acids in corn (Zea mays L.) oil from Ecuador. Asian J Pharm Clin Res 2017;10:150-3.

9. Kamal-Eldin A, Andersson R. A multivariate study of the correlation between tocopherolcontent and fatty acid composition in vegetable oils. J Am Oil Chem Soc 1997;4:375-80.

10. Carrillo W, Quinteros MF, Carpio C, Morales D, Vásquez G, Álvarez M, et al. Identification of fatty acids in sachainchi oil (Plukenetia Volubilis L.) from Ecuador. Asian J Pharm Clin Res 2018;11.

11. Weber PC, Leaf A. Cardiovascular effects of w3 fatty acids: Atherosclerotic risk factor modification by w3 fatty acids. World Rev Nutr Diet 1991;66:218-32

12. Simopoulos AP. New products from the agri-food industry: The return of n-3 fatty acids into the food supply. Lipids 1999;34 Suppl: S297-301.

13. Lopez-Miranda J, Perez-Jimenez F, Ros E, De Caterina R, Badimon L, CovasMI, et al. Olive oil and health: Summary of the II International Conference on Olive Oil and Health Consensus Report, Jaen and Cordoba (Spain) 2008. Nutri Metabol Cardiovasc Dis NMCD 2010;20:284-94.

14. Huffman SL, Harika RK, Eilander A, Osendarp SJ. Essential fats: How do they affect growth and development of infants and young children in developing countries? A literature review. Matern Child Nutr 2011;7 Suppl 3:44-65.

15. Kuipers RS, Luxwolda MF, Sango WS, Kwesigabo G, DijckBrouwer DA, Muskiet FA, et al. Postdelivery changes in maternal and infant erythrocyte fatty acids in 3 populations differing in fresh water fish intakes. Prostaglandins Leukot Essent Fatty Acids 2011;85:387-97

16. Luxwolda MF, Kuipers RS, Koops JH, Muller S, de Graaf D, DijckBrouwer DA, et al. Interrelationships between maternal DHA in erythrocytes, milk and adipose tissue. Is $1 \mathrm{wt} \%$ DHA the optimal human milk content? Data from four tanzanian tribes differing in lifetime stable intakes of fish. Br J Nutr 2014;111:854-66.

17. Ackatia-Armah RS, McDonald CM, Doumbia S, Erhardt JG, Hamer DH, Brown KH. Malian children with moderate acute malnutrition who are treated with lipidbaseddietary supplements have greater weight gains and recovery rates than those treatedwith locally produced cereallegume products: A community-based, cluster-randomized trial. Am J Clin Nutr 2015;101:632-45.

18. Michaelsen KF, Dewey KG, Perez-Exposito AB, Nurhasan M, Lauritzen L, Roos N, et al. Food sources and intake of n- 6 and n-3 fatty acids in low-income countries with emphasis on infants, young children (6-24 months), and pregnant and lactating women. Matern Child Nutr 2011;7 Suppl 2:124-40.

19. Carrillo W, Carpio C, Morales D, Vilcacundo E, Alvarez M. Fatty acids composition in Macadamia seeds oil (Macadamia integrifolia) from Ecuador. Asian J Pharm Clin Res 2017; 10:303-6.

20. Theresia JJ, Austin PC, Kelly V, Mary A, Wei L, Joyce LK, et al. Evaluation of fattyacid and mineral content of Tanzanian seeds and oils. J Food Comp Anal 2016;50:108-13.

21. Yoshida H, Tomiyama Y, Hirakawa Y, Mizushina Y. Variations in the composition of acyl lipids and triacylglycerolmolecular species of pumpkin seeds (Cucurbita spp.) followingmicrowave treatment. Eur J Lipid Sci Technol 2004;106:101-9.

22. Bernardo-Gil MG, Cardoso Lopes LM. Supercritical fluidextraction of Cucurbita ficifolia seed oil. Eur Food Res Technol 2004;219:593-7.

23. Yu W, Zhao Y, Chen J, Shu B. Comparison of twokinds of pumpkin seed oils obtained by supercritical CO2 extraction. Eur J Lipid Sci Technol 2004;106:355-8.

24. Applequist WL, Avula B, Schaneberg BT, Wang YH, Khan IA. Comparative fatty acid content of seeds of four Cucurbita species grown in a common (shared) garden. J Food Compos Anal 2006;19:606-11.

25. Tsaknis J, Lalas S, Lazos ES. Characterization of crude andpurified 
pumpkin seed oil. Grasas Aceites 1997:48:267-72.

26. Kamel BS, de Man JM, Blackman B. Nutritional, fattyacid and oil characteristics of different agricultural seeds. J Food Technol 1982;17:263-9.

27. CFSAN/Office of Nutritional Products, L.A.D.S. Letter Responding to Health ClaimPetition dated August 28, 2003: Monounsaturated Fatty Acids from Olive Oil andCoronary Heart Disease (Docket No 2003Q0559); 2004.

28. EFSA. Scientific opinion on the substantiation of health claims related topolyphenols in olive and protection of LDL particles from oxidative damage (ID1333, 1638, 1639, 1696, 2865), maintenance of normal blood hdl cholesterolconcentrations (ID 1639), maintenance of normal blood pressure (ID 3781), "anti-inflammatory properties" (ID 1882), "contributes to the upper respiratory tracthealth" (ID 3468), "can help to maintain a normal function of gastrointestinal tract"(3779), and "contributes to body defences against external agents" (ID 3467) pursuant to article 13(1) of regulation (EC) No 1924/2006. Eur Food Safe Authority J 2011;9:2033-58

29. Bondia-Pons I, Schroder H, Covas MI, Castellote AI, Kaikkonen J, Poulsen HE, et al. Moderateconsumption of olive oil by healthy European men reduces systolic blood pressurein non-Mediterranean participants. J Nutr 2007;137:84-7 